\title{
Afogando em nomes: temas e experiências em história econômica*
}

\author{
João Fragoso
}

\section{Império ultramarino e sociedade colonial}

Uma das intenções deste trabalho é analisar a história colonial, tendo como pano de fundo o Império luso. Nas últimas décadas, as pesquisas sobre as sociedades coloniais ibéricas e os Impérios Ultramarinos passaram por diversas mudanças. Hoje, sabe-se que elas não eram meros apêndices da Europa e, portanto, sua dinâmica social ultrapassava o mercantilismo. Mais recentemente, as leituras críticas da noção de Absolutismo ${ }^{1}$ abriram caminho para uma revisão das relaçóes entre Metrópole e Colônia. Nesta esteira, autores como J. Greener sublinharam a idéia de autoridades negociadas como meio para se entender melhor aquelas relaçōes. ${ }^{2}$ Ao invés de metrópoles onipotentes e colônias submissas, teríamos contínuas negociações entre ambas.

Mais do que isto, os impérios, como o português, deixaram de ser vistos como uma simples colcha de retalhos, cuja unidade seria dada pela obediência à mesma coroa. Apesar de todas as diferenças entre as sociedades que compunham o Império luso, começou-se a perceber a existência de fenômenos que aproximavam tais paragens. É certo que Portugal, com suas estruturas aristocráticas e camponesas, era diferente da sociedade escravista da América lusa e, igualmente, esta não se confundia com o Reino de Angola e, muito menos, com o Estado da Índia. Contudo, para além destas dis-

\footnotetext{
* O texto expõe algumas preocupações temáticas do grupo de história econômica (séculos XVIIXIX), sob minha orientação, no LIPHIS (Laboratório Interdisciplinas de História Social) e no PPGHIS (Programa de Pós-graduação em História Social). Vou-me deter, principalmente, em três discussóes: império português, hierarquia social e processos de mudanças na sociedade colonial. Várias das idéias a seguir são hipóteses de investigações ainda em curso e, portanto, sujeitas a reparos.
}

Topoi, Rio de Janeiro, dezembro 2002, pp. 41-70. 
tinções óbvias, não há como negar o papel fundamental exercido pelos comércios ultramarinos na reprodução das sociedades apreendidas. Basta lembrar que o tráfico atlântico de cativos para a América tinha como uma de suas moedas de troca, em Angola, os panos da Índia. Este negócio viabilizava a escravidão brasileira, a reiteração de sociedades africanas e parte da economia do Estado da Índia, além de gerar ganhos para o Reino. Assim, tais ligações imperiais permitiam a manutenção daquelas sociedades com suas respectivas diferenças estruturais.

Entretanto, estes laços não terminavam no simples comércio. Na verdade, cabe investigar a "natureza" de tais trocas, que ocorriam num mercado pré-industrial. $\mathrm{Ou}$, se preferirem, marcado pelas práticas do Antigo Regime, onde a política tinha um papel decisivo. Portanto, aquele comércio estava longe de ser regulado pela livre concorrência. As alianças entre negociantes/oficiais e as mercês concedidas pelo rei consistiam, entre outras, em móveis do mercado imperial. ${ }^{3}$

Do mesmo modo, o mar de Camóes podia aparecer, aos olhos dos integrantes da antiga sociedade portuguesa, como um espaço de oportunidades. Daí a figura do "fidalgo errante", criatura da expansão ultramarina. Em geral, vinham do braço popular e/ou da pequena nobreza lusa e seus feitos no ultramar os alçaram a outra qualidade. Porém, com raras exceçôes, não eram reconhecidos pela velha hierarquia reinol, ou seja, suas chances no reino continuavam reduzidas - mas o mesmo não ocorria nas conquistas. Vários se transformaram em conquistadores do Nordeste, do Rio de Janeiro e do Rio Grande de São Pedro, formando as "melhores famílias da terra” dos trópicos. Antes disso, tinham passado pelos Açores, lutado na Índia ou servido na África.

Indo mais adiante, a presença do Antigo Regime não só era percebida nas rotas marítimas ou nos negócios cotidianos internos de Angola ou de Portugal, mas também tal presença deixou suas marcas em instituições como a Câmara Municipal e a Santa Casa de Misericórdia. De origem reinol, elas se espalharam por diferentes espaços ultramarinos: de Recife a Macau. Mais do que isto, as Câmaras serviam, à semelhança das lusas, como locus de negociação entre a "nobreza da terra" local e os poderes do centro. ${ }^{4}$ Portanto, em meio àqueles vários vínculos ultramarinos, não há por que se espantar com a existência de redes políticas que, partindo de Goa ou do 
Rio de Janeiro, chegavam ao paço lisboeta, sendo base de conflitos e negociações nos rumos do Império. ${ }^{5}$

Por conseguinte, não se trata apenas de averiguar a presença de laços entre as diversas partes do Império. Que este ultrapassava a simples condição de um emaranhado de conquistas submetidas a uma Metrópole é fácil de ser visto. $\mathrm{O}$ mare lusitanum era um Império e, como tal, precisa de um arcabouço teórico mais refinado para explicar sua lógica. O que importa é analisar a "natureza" daqueles liames — internos e externos — e, com isto, deslindar a dinâmica imperial. Uma pista parece ser o Antigo Regime.

\section{Hierarquia e exclusão social e o Antigo Regime nos trópicos}

Estas novas visóes sobre Império, inevitavelmente, trariam conseqüências no entendimento da sociedade colonial. Sob esta ótica, outro tema investigado é o das hierarquias sociais na América lusa, em particular, da exclusão social. Considera-se que tal sociedade fora construída sob a égide do Antigo Regime e, mais que ela, entre o século XVI e XIX, vivera uma série de mudanças sociais e nas suas formas de acumulação de riqueza. Um bom exemplo disso foram as transformações do Centro-Sul, na passagem do século XVII para o seguinte. No primeiro, nas cercanias da Guanabara, prevaleciam a produção de açúcar e o domínio de uma nobreza da terra. Ao longo do setecentos, ocorreram o definhamento do açúcar carioca e a consolidação de uma poderosa comunidade de negociantes residentes, com afazeres transatlânticos e nas rotas internas coloniais, sendo tais mudanças acompanhadas pela multiplicação de vilas, de novas produções em São Paulo e nas Minas, além da interiorização de rotas comerciais no Centro-Oeste. O Rio Grande de São Pedro setecentista, por exemplo, presenciou a migração de açorianos e de paulistas (inclusive de frações de suas elites) e o apresamento de gados cedeu lugar às estâncias, ligadas ao abastecimento das Gerais e do Rio. ${ }^{6}$

Em todas estas áreas, a estratificação social tornou-se mais complexa com a chegada massiva de reinóis e de escravos africanos, a multiplicação de forros e uma maior divisão social do trabalho, a exemplo do aumento dos ofícios artesanais. ${ }^{7}$ Entretanto, apesar destas transformações, a exclusão social do seiscentos permaneceu, porém com novos matizes. Na verda- 
de, mais do que derivar a exclusão do trabalho escravo ou de uma concentração de rendas, é fundamental entender os mecanismos que permitiram a sua recriação temporal. Para tanto, parte-se de alguns pressupostos. ${ }^{8}$

Antes de tudo, a hierarquia social colonial deriva daquilo que denomino de Antigo Regime nos trópicos. Portanto, além de seus aspectos econômicos, seria forjada por vetores políticos e culturais, onde os grupos sociais se percebiam e eram percebidos por suas qualidades. ' Como se sabe, na antiga sociedade lusa cabia ao governo cuidar do bem comum da República: dirigir a organização social e política das regiōes, sendo isto feito pelas pessoas de melhor qualidade da localidade — reunidas na Câmara - e pelos ministros do Rei, ambos subordinados à Coroa. No caso do Rio de Janeiro seiscentista, os camaristas fiscalizavam o abastecimento, controlavam o açougue público e o trapiche do açúcar; entre outros afazeres. Um ministro, como o Provedor da Fazenda Real e Ouvidor do Porto, respondia pelo erário da Coroa e pelas questóes portuárias.

A partir do governo da República, a hierarquia social colonial começava a adquirir suas feições. Seguindo um velho costume luso, os postos camaristas e os ofícios régios - se concedidos como propriedade - podiam ser hereditários. $\mathrm{O}$ acesso à Câmara pressupunha pertencer à governança da terra, ou seja, descender de antigos camaristas. O cargo de Juiz de Órfãos podia passar de pai para filho. A soma destes aspectos do "governo" contribuiu para a formação de uma nobreza da terra e, conseqüentemente, de uma hierarquia social estamental e excludente. Em outras palavras, algumas famílias detinham parte do mando local, por terem melhor qualidade que as demais mortais. Como tais, as primeiras familias interferiam na vida da República e nos seus negócios, em particular no mercado. Neste ambiente, o cabedal (riqueza material) era visto como meio para sustentar a qualidade. ${ }^{10}$

O processo de montagem da sociedade colonial fluminense e de sua elite ilustra bem estes cenários. Coubera à Coroa a ocupação da região, porém com a decisiva participação de segmentos das elites vindas de outras áreas americanas. Estes últimos, no melhor estilo da época, colocaram suas fazendas, suas parentelas, seus escravos e flecheiros ao serviço do rei. Em troca, receberam mercês, como de sesmarias e ofícios régios. Da mesma forma, a tais conquistadores caberiam os postos da Câmara da "cida- 
de", transformando suas famílias nos homens bons da região. Portanto, a organização da nova sociedade não fora dirigida apenas pelas autoridades vindas do Reino ou do Governo Geral do Brasil, mas também pelos conquistadores. Neste sentido, a constituição do Rio colonial seria, simultaneamente, de uma hierarquia social de matizes do Antigo Regime, sendo o seu topo dominado pelos conquistadores, agora transformados na nobreza da terra.

A princípio, isto significa que o pertencer à elite não derivava da riqueza material: engenhos de açúcar ou imensos ativos comerciais. Só isto não habilitava à direção da "República" e aos altos escalóes da hierarquia social. Disto deriva, ao menos, um fenômeno: além dos escravos e dos pobres livres, os donos de grandes fortunas podiam estar afastados daqueles postos e direitos. Estes últimos, em seus negócios, estavam subordinados a famílias da governança da terra e estas podiam ter fortunas menores. ${ }^{11}$ Assim, parece-me que a noção de exclusão social adquire feiçôes mais refinadas e complicadas.

Isto fica patente quando lidamos com a relação qualidade e cabedal. Relação central no Antigo Regime europeu e ainda mais importante nos trópicos, pois, nestes, prevalecia uma economia mercantil escravista. Diante desta última informação, o perfil da elite e os contornos da hierarquia colonial tornam-se mais interessantes. Parte da direção da sociedade colonial estava nas mãos de uma nobreza bem diferente da européia. Aquela descendia, em geral, do braço popular e não das melhores casas da aristocracia portuguesa. ${ }^{12}$ Da mesma forma, não vivia de rendas, dadas por um campesinato ou pelo Rei. Muito menos, seus afazeres se resumiam à guerra ou à administração da coisa pública, como no Velho Mundo.

Portanto, não surpreende que as melhores famílias da terra do seiscentos apareçam como apresadoras de índios e traficantes de escravos. Para elas, tais atividades não diminuíam a sua qualidade, pelo contrário, serviam para mantê-la. Para a nobreza - e a sociedade — algo a distinguia dos demais comerciantes: a sua qualidade, proveniente da conquista e, conseqüentemente, de pertencerem à governança da "República". Segundo sua concepção, o cabedal e as maneiras de consegui-lo estavam subordinados àquela "qualidade primeira", sendo isto válido no seiscentos, mas também no século seguinte. Na verdade, os nobres se aproveitavam de sua condição polí- 
tica para realizar acumulações comerciais "como vis mercadores" e/ou por meio de alianças com negociantes.

Por sua vez, tal traço dos "fidalgos tropicais" deve ter criado uma visão mais flexível sobre as fortunas provenientes do comércio e do trabalho. Assim como não seria surpresa que o enriquecimento mercantil influísse nos contornos da hierarquia social. Porém, há que se ter cuidado com a magia da moeda, enquanto agente corrosivo de uma sociedade estamental. De igual modo, o que foi dito não elimina, em tese, as tensões sociais entre os que possuíam riqueza, mas não poder, com a elite. Seja como for, os traços da elite permitem uma visão menos esquemática da estratificação colonial, o que pode ajudar a entendê-la melhor.

Neste sentido, freqüentemente se escreve sobre a adoção de valores culturais da elite senhorial por parte dos lavradores, dos forros e dos índios, esquecendo-se do oposto. Parte da nobreza da terra fluminense, de São Paulo e do Rio Grande de São Pedro casou com lideranças indígenas e, portanto, seus descendentes eram mestiços, pelo menos nos primeiros tempos coloniais. As cartas jesuíticas quinhentistas estão recheadas de exemplos de colonos "brancos" adotando costumes indígenas, como a poligamia e a antropofagia. Bartolomeu Bueno, no seiscentos, devia ter seus motivos para querer ser conhecido como Anhangüera. ${ }^{13}$ Ainda no início do século XVIII, tal nobreza mestiça — alguns com sangue judeu — continuava a incorporar genros militares e comerciantes, vindos de escalóes abaixo dos Grandes de Portugal.

Portanto, o fato de a hierarquia social colonial ser marcada pela exclusão não implicava que a elite estivesse numa redoma, afastada dos demais grupos. Em realidade, ao que parece, aquela origem social e cultural teria um papel decisivo na estratificação considerada, ou melhor, na sua repetição temporal.

Estas questôes obrigam a ter mais cuidado com o estudo das diferenças sociais na Colônia, pois elas não eram mantidas a ferro e fogo. O poder de mando da nobreza não decorria de um dom divino, dado para sempre. Portanto, a sociedade colonial continha seus mecanismos de reprodução e de elasticidade, entre os quais as práticas de negociação. Desnecessário dizer que tais negociações possuíam seus limites. Um deles era próprio da 
hierarquia estamental. Cabia ao grupo de melhor qualidade a ingerência no governo da sociedade, inclusive nos rumos da economia. Daí a importância da idéia de estratégias e, com ela, a de conflitos, como instrumento de análise para o entendimento do Antigo Regime nos trópicos.

Antes de tudo, aquelas estratégias deviam traduzir-se em redes sociais que garantissem à nobreza o exercício do mando. Em outras palavras, a sociedade tinha de "consentir" em tal hegemonia. A contínua reinvenção da hierarquia estamental pressupunha da nobreza atitudes como práticas parentais entre suas famílias; constituição de redes de alianças com frações das elites regionais da América lusa e com autoridades metropolitanas inclusive com as de Lisboa; casamentos com negociantes etc. ${ }^{14}$ Entretanto, talvez mais vitais fossem os dons e os contradons com os chamados grupos subalternos. Por exemplo, a nobreza - em ofícios régios - concedia serventias e postos militares a integrantes daqueles grupos; estabelecia com eles relações de parentesco fictício e os "auxiliava” diante da justiça etc. As melhores famílias da terra compravam engenhos desfabricados para garantir a sua ascendência nas populaçôes dos arredores das capelas das "fábricas". ${ }^{15}$

Sublinhar a presença da negociação não implica eliminar as tensões sociais: quilombos e rebeliōes em geral. Contudo, convém ter cautela com imagens apressadas. A sociedade colonial não pode ser encarada como um campo de concentração para escravos e índios. Ou, o que é o mesmo, como um asilo de paranóicos para a elite, portadora do medo crônico de revoltas das "massas". É imprescindível uma visão mais requintada sobre os modos de reiteração da estratificação colonial e de sua exclusão social.

Vale relembrar que, quando falo de estratégias, não me estou referindo somente à nobreza ou aos grandes negociantes. Na verdade, as negociações entre os diferentes segmentos da sociedade pressupunham que eles tinham as suas próprias estratégias de vida. Assim, as relações de compadrio entre nobres e pequenos lavradores ou com escravos, por exemplo, não podem ser reduzidas a uma simples artimanha senhorial. Os lavradores possuíam também seus motivos para tal opção. Da mesma forma, os casamentos mistos entre livres e forros devem ser entendidos a partir das suas visões de mundo e estratégias de vida. ${ }^{16}$ Os escravos e outros grupos subalternos eram portadores de formas de pertencimento culturais, práticas fa- 
miliares e maneiras de solidariedades que não se reduziam às chamadas relaçôes de produção. ${ }^{17}$ Sendo mais incisivo e sem menosprezar a chamada circularidade cultural: os cativos e os pequenos lavradores possuíam mais de dois neurônios. Deste modo, não eram criaturas das elites. Se, para estas, suas estratégias sociais significavam a manutenção do poder, para os grupos subalternos, tê-las podia representar a própria sobrevivência física.

Cabe aqui relembrar, mais uma vez, que estamos diante de uma hierarquia estamental. ${ }^{18}$ Isto nos leva a pensar a questão da ascensão social sob um novo ângulo. Pois, se os grupos subalternos tinham uma cultura própria, que não se esgotava no modus vivendi senhorial, deve-se perguntar o que eles compreendiam por "ascensão" na dita sociedade.

Sem querer aprofundar este tema, para os grupos considerados, a combinação entre práticas parentais com as de vizinhança e os entendimentos com fraçôes das elites auxiliavam, em tese, a melhoria de suas vidas. De igual maneira, agiam numa economia também mercantil, onde a própria nobreza sustentava sua qualidade através do tráfico. Portanto, o trabalho e o comércio, a princípio, não tinham o mesmo estigma social do Velho Mundo. Certos escravos compravam alforrias e seus descendentes podiam adquirir cativos e terras. Contudo, o que esta melhoria de vida e, inclusive, de qualidade significava — em temos de referências culturais — para aqueles novos lavradores escravistas, comerciantes, artesãos livres ou mesmo donos de moendas? Responder a esta pergunta é vital para compreender uma sociedade onde a alforria não era algo episódico, mas, sim, tinha densidade demográfica. Para complicar ainda mais este quadro: apenas o enriquecimento não garantia a ascensão social, que dependia de outras relações, que não as mercantis. Afinal, como a sociedade entendia tais movimentos? ${ }^{19}$

Entretanto, voltemos à questão inicial: a exclusão social não era sinônimo de tensão social crônica. Até porque muitos dos conflitos sociais não se resumiam às lutas entre livres e escravos. Para começar, bandos em disputas pelo poder tinham uma composição social parecida: nobreza, negociantes, ministros do Rei, lavradores, cativos etc. ${ }^{20}$ Foram, ainda, freqüentes os relatos de senhores que iam a confrontos bélicos - contra os inimigos $\mathrm{da}$ Coroa, desafetos pessoais ou quilombolas - acompanhados de seus escravos africanos e flecheiros indígenas. Isto informa sobre práticas de dons 
e contradons entre estes segmentos, ou melhor, de negociações. Neste sentido, são ilustrativas duas passagens do Rio colonial.

O Reitor da Companhia de Jesus e o Ouvidor do Rio de Janeiro, em 1691, mandaram cartas a Lisboa, denunciando agressões contra a Companhia em Campos:

Os negros de José de Barcelos e outros mais de Martim Correia Vasques (...) armados com flechas, dardos e armas de fogo foram a um dos currais dos ditos padres e investindo aos tiros aos negros que assistiram nele (...) deixando muitos feridos (...) ameaçando os que [retornassem] aquele sítio os haviam de matar e ainda não satisfeitos queimaram as casas e derrubaram o dito curral.

A devassa de tal crime não foi levada adiante, "em razão de [José Barcelos e Martim Vasques] serem régulos e temerem as testemunhas de jurarem a verdade pelo dano que disso lhe podia sobrevir". ${ }^{21}$

Em 1745, em um requerimento para Lisboa,

(...) os pardos forros da cidade do Rio de Janeiro e seu recôncavo, no Brasil, que eles zelozos do real serviço desejam fazer um regimento de três tropas auxiliares de cavalo e estarem prontos para todas as ocasiōes do real serviço com cavalos, armas e fardas, dignando-se V.M. criar o dito regimento e nomear para coronel dele a João Freire Alemão de Cisneiros.

José Barcelos, Martim Correia Vasques e João Freire Alemão pertenciam à nobreza da terra ou, como afirma a primeira carta, eram "régulos": "pessoas muito poderosas naquelas partes”. A correspondência de 1691 narra, a princípio, uma situação que se enquadra na visão corrente de uma sociedade estamental: a hierarquia era mantida pela força, os grupos subalternos apareciam como oprimidos e sem massa encefálica. Afinal, em meio às disputas dos poderosos, as testemunhas preferem ficar mudas e os escravos foram usados como "bucha de canhão". Porém, se olhamos mais atentamente para estes fatos, algumas coisas mudam. Barcelos e Vasques atacaram seus desafetos não com mercenários suíços e, sim, com seus escravos armados, ou seja, os que personificavam a exclusão social. Considerando que estes cativos não eram simples robôs programados para matar, mas pessoas, a relação senhorial adquire um novo significado. A possibilidade 
de portarem armas implicava, ao menos, em "acordos" com seus donos. Ao que parece, aqueles senhores não temiam que os cativos armados se voltassem contra eles. Quanto ao comportamento das testemunhas, homens livres, vale relembrar que o conflito era entre frações da elite. Desnecessário dizer que os jesuítas não eram pobres servidores de Deus, seu poder político e militar já tinha sido medido em outras oportunidades do seiscentos fluminense. Portanto, as testemunhas, ao não deporem, na verdade, tomaram o partido de um segmento da elite contra outro.

O segundo relato é, talvez, mais interessante. O fato de forros pretenderem organizar um regimento de cavalaria insinua a possibilidade de mobilidade nos estratos mais subalternos da sociedade. Afinal, eram pardos forros em condições de custear armas e cavalos, o que pressupunha recursos para tanto. Portanto, tinham saído da escravidão e possuíam certo cabedal. Por seu turno, a escolha de João Freire para comandá-los implica na existência de entendimentos entre aqueles forros e uma família da nobreza. Curiosamente, neste ambiente de mobilidade e de negociações, que referendava a hierarquia social excludente, a resposta de Lisboa fora negativa. Segundo a sua decisão, a existência de "corpos de infantaria da ordenança separados de pardos e bastardos (...) pode ser em grande prejuízo desse Estado, e muito contra a quietação e sossego desses povos, que se faz digno de todo cuidado e atenção" ${ }^{22}$ Parece que Lisboa tinha mais receio das "inquietaçôes" dos "pardos e bastardos" do que a própria nobreza da terra: os primeiros que seriam atingidos por ameaças à hierarquia social.

Ambas as citaçóes indicam a presença, nos meandros da sociedade escravista, de mecanismos que permitiam a reiteração de uma hierarquia social excludente. Em outras palavras, os dois casos informam que tais mecanismos garantiam — na falta de uma melhor palavra — o poder social da nobreza da terra. Poder este que, em certas circunstâncias, inibia a ação da administração colonial. A impotência do Ouvidor nos acontecimentos de 1691 ilustra bem isto. Na verdade, a nobreza, para participar do governo da República ou, ainda, manter sua qualidade estamental numa economia mercantil, tinha de ter redes de poder social. 


\section{Processos de mudanças na sociedade colonial}

O Antigo Regime possui uma história e com o dos trópicos ocorre o mesmo. As configurações do último mudaram aos caprichos da dinâmica imperial e, em particular, da lógica da sociedade colonial. Em função destes parâmetros gerais, as transformações não ocorriam de maneira aleatória, mas sim num cenário definido por alguns aspectos estruturais, entre eles a proeminência da política nas relaçôes cotidianas, em particular sobre a economia, e a permanência da hierarquia social estamental de base escravista.

Para o estudo de tal tema, utilizarei o exemplo do Rio de Janeiro na virada do século XVII para o seguinte. Em 1700, os tributos da cidade insinuavam a continuidade de uma economia ainda marcadamente seiscentista. Os dízimos reais, provavelmente de acentuada origem agrícola, prevaleciam. Somavam 18:666 $\$ 666$ por ano ou 35,6\% da arrecadação total, estimada em 57:304\$569. A novidade ficava a cargo de impostos, como os dos couros e da alfândega. O primeiro tributava o comércio com a estremadura sul da América lusa. O segundo pode ser tomado como índice nas ligações entre o Rio e as rotas comerciais ultramarinas (entrada das frotas no porto). Neste ano, a arrecadação do último foi de 1:496\$273, o equivalente a $2,6 \%$ do total fiscal e a menos $1 / 10$ dos dízimos. Estes números demonstram a continuidade de uma frágil economia exportadora de segunda classe. ${ }^{23}$

Em 1734, teremos um outro quadro. Novos impostos apareciam, como o das passagens dos rios Paraíba e Paraibuna para as Minas, os direitos de escravos que iam para as Minas e o da guarda da costa (responsável pela proteção das frotas). Estes tributos informavam sobre o alargamento das rotas comerciais do Rio, seja no interior da América, seja no ultramar. Talvez mais significativo seja o desempenho dos dízimos da alfândega. Naquele ano, o fisco recolheu cerca de 270 contos de réis, dos quais 160 só na alfândega, ou quase $60 \%$ do total. Quanto aos dízimos reais, ficaram em 12 contos, portanto, menos de 1/20 do arrecadado na alfândega. Deste modo, a cidade estava abandonando sua antiga base agrária para se converter num ponto de convergência dos fluxos comerciais do Império português. ${ }^{24}$ 
Estas mudanças, evidentemente, indicavam que os engenhos de açúcar e seus senhores estavam cedendo espaço para uma "economia portuária” e para os homens de negócios. O crescimento da produção aurífera, a multiplicação das rotas comerciais e o adensamento demográfico da cidade trariam outras mudanças. O Reino teria um maior cuidado no controle administrativo sobre a Colônia, inclusive por meio de contingentes militares e novos "funcionários". De igual forma, os olhos dos negociantes de grosso trato, reinóis, voltaram-se para a cidade.

Antes de prosseguir, algumas coisas devem ficar claras. A descoberta do ouro não fora um fenômeno fortuito. Na verdade, as autoridades metropolitanas já o procuravam desde o quinhentos. Além disto, tal busca foi vista como algo fundamental por São Paulo e pelo Rio de Janeiro, áreas com economias marginais diante das plantations nordestinas do produtorei. Para o Rio de Janeiro, cujo açúcar o comércio reinol preteria, as investidas no sertão eram a tentativa de melhorar a reprodução de sua sociedade. Daí a participação de integrantes da nobreza da terra seiscentista nestas expedições. Assim, a descoberta das minas decorreu da lógica de reiteração da sociedade colonial e não de um feliz acaso. Por seu turno, os bandeirantes paulistas que acharam os metais - como os Rodrigues Paes e os Bueno - tinham ligações parentais com os fluminenses. ${ }^{25}$ Ao mesmo tempo, as expedições foram custeadas, em parte, pela "fazenda" de sertanistas da nobreza da terra, ou seja, entenderam tal façanha como vassalos do Rei, porém enquanto uma conquista sua. ${ }^{26}$

Este pano de fundo ajuda a compreender melhor a fixação social da produção mineira, assim como os seus impactos sobre o Rio de Janeiro. Certo é que a economia da Guanabara não passava, em finais do século XVII, por uma fase brilhante. O início da década de 1690 foi marcado pela escassez de numerário, pela queda nas vendas de açúcar e pelas dificuldades na compra de escravos africanos. Mais de 10 engenhos, em um total estimado de 110 a 130, passaram para novas mãos. Entretanto, a elite local já tinha uma cultura econômica para enfrentar dissabores. A maior parte daquelas fábricas foi comprada por parentes ou aliados dos senhores falidos. Portanto, terras, escravos e capelas permaneceram nos mesmos segmentos da elite. Afora isto, houve um maior movimento de casamentos 
endógenos na nobreza. A combinação destes fenômenos protegeu, ao menos, parte das famílias senhoriais e, ainda, permitiu uma maior concentração de terras e poder. Várias casas quinhentistas podem ter perdido a sua qualidade, porém a hierarquia estamental e a hegemonia da velha nobreza foram asseguradas.

Além disto, a produção nas Minas e o seu abastecimento iriam ampliar as fortunas das famílias nobres que ultrapassaram os azares da década de 1690. Não é sem motivo que José de Andrade Soutomaior, descendente do quinhentos, arrematou, em 1704, os dízimos da alfândega. Na década seguinte, outros integrantes da velha nobreza apareciam como fiadores de impostos: Salvador Correia de Sá, em 1713, e Francisco de Oliveira Paes e Manuel Freire, no final do decênio. Existiam, ainda, nobres com rotas comerciais no sul e no tráfico de escravos, a exemplo de Francisco de Almeida Jordão e filhos e dos Cherem. Outras famílias, como os Gurgel, enriqueceram via exploração mineira. Francisco de Gurgel do Amaral chegou a oferecer um donativo de 300 mil cruzados, em 1714, para a construção da fortaleza da Ilha das Cobras, pedindo, em troca, mercês: o foro de fidalgo, o posto de alcaide-mor de Santos e o de governador da dita fortaleza. Por último, algumas daquelas famílias procuraram estreitar seus vínculos parentais com os paulistas. Neste sentido, o alcaide-mor do Rio, Tomé Correia Vasques, filho do mestre-de-campo Martim Correia Vasques, casaria, em 1706, com a filha de Gaspar Rodrigues Paes, guarda-mor das Minas. Esta última medida ampliava, em tese, a ascendência de segmentos da nobreza fluminense sobre a nova conquista. ${ }^{27}$

Portanto, os fenômenos derivados da descoberta aurífera não se deram numa área vazia. Ocorreram numa sociedade colonial preexistente. Assim, no Rio de Janeiro, as autoridades, os grandes negociantes metropolitanos e os demais emigrantes encontraram uma hierarquia social já estabelecida. Em outras palavras, aqueles "estrangeiros" tiveram que lidar com uma nobreza, cujas redes sociais se estendiam pela capitania e por outras elites regionais.

A presença de tais redes no cotidiano dos "estrangeiros" pode ser vista através dos seus currículos. Ainda na década de 1740, os candidatos ao posto de mestre-de-campo da Infantaria paga — um dos mais altos da hierar- 
quia militar - frisavam a façanha de, quando jovens, em 1712, terem prendido integrantes da nobre família tupiniquim Amaral Gurgel. Tal evento deve ter marcado a sociedade local e o imaginário bélico destes oficiais de carreira, pois ele aparecia lado a lado de batalhas na Europa e nos confins da América. ${ }^{28} \mathrm{Na}$ mesma década de 1710, o governador Francisco da Távora se queixava a Lisboa da impunidade de Manuel Homem e de Francisco de Oliveira Leitão, homens principais da Ilha Grande, que impediam, pela força, as sindicâncias dos soldados da Coroa. ${ }^{29}$ Em 1725, d. Antônia Maria de Lima exigia a prisão de Manuel Freire Alemão, por não querer pagar as dívidas para com seu falecido marido. Segundo dona Antônia, Freire Alemão se valia para tanto da sua condição de "homem poderoso" ${ }^{30}$ Estes casos falam por si mesmos. Nestes tempos, a nobreza continuava a ser vista enquanto tal pela população: isto é, como as melhores famílias da terra. Algo que, portanto, as autoridades vindas do Reino não podiam menosprezar.

Diante disto, foi inevitável o estabelecimento de negociações entre frações da nobreza com altos representantes da Coroa. Neste sentido, temos o casamento, em 1717, de Helena da Cruz, neta de Francisco de Almeida Jordão, com o mestre-de-campo e ex-governador do Rio, Manuel de Almeida Castelo-Branco. A filha do casal, nascida em 1719, teria por padrinho o conde de Assumar. Anos antes, José Cherem se tornava esposo da manceba do capitão da Fortaleza de São Sebastião, João Cerqueira da Costa. ${ }^{31} \mathrm{O}$ mesmo pode ser visto no matrimônio, em 1720, entre a filha de José de Andrade Soutomaior com o rebento do mestre-de-campo Gregório de Morais Castro Pimentel.

Com certeza, houve um maior controle metropolitano sobre a vida na cidade. A importância da Câmara, tradicional locus de poder da nobreza, foi reduzida. Em finais da década de 1720, os impostos administrados pelos camaristas passaram para a Fazenda Real, sendo arrematados em Lisboa. ${ }^{32}$ Entretanto, as velhas famílias da terra continuavam a ocupar postos-chave da República, em particular de sua economia. Manuel Correia Vasques, filho do já referido Martim Vasques, no ano de 1703 adquiria o cargo de juiz da Alfândega. Bartolomeu da Siqueira Cordovil, marido de Margarida Pimenta de Melo, da nobreza fluminense, em 1716, conseguia a propriedade do ofício de provedor da Fazenda Real. Assim, se por um 
lado a nobreza perdia poder, por outro continuava a influir, via política, nos negócios mercantis da cidade. Aqui não custa lembrar duas coisas. Primeiro, o Rio se afirmava, cada vez mais, como centro das rotas comerciais da Colônia e do Império. ${ }^{33}$ Segundo, tais negócios eram realizados num mercado pré-industrial, portanto, dependiam da "boa vontade" daqueles dois oficiais. Basta lembrar que ambos podiam interferir em contratos, como dos direitos dos cativos e da alfândega, vitais numa economia escravista em expansão. Isto, inevitavelmente, levava os grandes negociantes do Reino a agirem com certo cuidado diante dos nobres citados. Como diria Francisco Pinheiro, um dos maiores negociantes da época: "Deus [me] livre de semelhantes tribunais como são as alfândegas". ${ }^{34}$

Provavelmente, tinha razão. Em 1725, os negociantes da praça do Rio pediam que não fossem cobrados os dízimos da alfândega para os produtos oriundos dos portos americanos. Esta reivindicação ia contra os interesses do arrematador de tais impostos, em geral grande comerciante reinol, mas auxiliava muito o comércio interno e a acumulação mercantil daí oriunda. O provedor da Fazenda do Rio tomaria partido dos comerciantes da praça. Entre 1723 e 1726, os mesmos homens de negócio protestaram recorrentemente contra a precariedade dos serviços da alfândega e dos privilégios dos grandes contratadores. Estes, através de seus correspondentes, tinham o direito de despachar logo suas mercadorias, em detrimento dos demais. O provedor e o juiz da Alfândega, mais uma vez, depunham a favor dos "suplicantes" e condenavam os privilégios dos arrematadores. No ano seguinte, o contratador da nau da Capitania, Jerônimo Lobo Guimarães, denunciava a "soberba dos moradores do Rio". Eles não queriam pagar tal imposto, pois alegavam que isto era obrigação dos capitães das naus vindas à cidade. $\mathrm{O}$ juiz da Alfândega, para não perder o hábito, saiu em defesa dos moradores da cidade. Em 1735, chegava a vez de o contratador das entradas de escravos, Pedro Dauvegner, se desentender com o provedor da Fazenda Real, Francisco Cordovil Siqueira de Mello, filho de Bartolomeu Cordovil. Para o provedor, Dauvegner não cumprira à risca o seu contrato.

Mais de vinte anos depois, em 1753, José Bezerra de Seixas, um dos maiores comerciantes ultramarinos lusos, repetia as queixas de seus pre- 
decessores: a isenção dos navios vindos dos portos da América, inclusive dos couros do sul, de não pagarem os dízimos da Alfândega. Contra esta reclamação, o juiz da Alfândega da época, Antônio Martins de Brito, mantinha a posição de defender os negociantes da cidade. No mesmo ano, a saída dos navios do Rio para o Reino foi ameaçada pela suspeita de irregularidades. Contra isto os negociantes da praça protestaram, e o caso foi parar no Tribunal da Relação do Rio. Alguns dos desembargadores votaram a favor dos negociantes, entre eles Matias Pinheiro da Silveira Botelho. Coincidentemente, em 1755, este senhor se casava com Antônia Viana de Castro, viúva de um descendente dos Amaral Jordão. ${ }^{35}$

Poderia multiplicar os exemplos sobre a interferência de frações da nobreza da terra nos rumos da economia mercantil do Rio. Curiosamente, estes casos ilustram situaçôes em que nobres agiram a favor dos homens de negócios da praça ou, sendo mais preciso, no crescimento do comércio regional e ultramarino da cidade, contribuindo, com isto, para a transformação do Rio no centro do Império e na formação de uma poderosa comunidade de negociantes de grosso trato.

Contudo, isto não significou que o conjunto da nobreza agiu de comum acordo ou como aliado incondicional dos chamados negociantes da praça. As divergências no interior da nobreza continuavam e houve vários atritos com os comerciantes locais. Em contrapartida, houve alianças de nobres com os poderosos mercadores lusos. ${ }^{36}$

Por conseguinte, há ainda muita coisa a ser investigada no processo de transformação do Rio de uma economia açucareira de segunda classe para a principal praça comercial do Império português. Contudo, já é possível arriscar algumas hipóteses.

Antes de tudo, como disse, existia um Império e a cidade não era uma terra de ninguém. Ao invés disto, havia uma sociedade de Antigo Regime nos trópicos. Portanto, a Coroa, assim como os que aqui chegaram, tiveram de negociar com a elite da terra, ou melhor, com as redes sociais preexistentes. Neste sentido, as experiências vividas pela nobreza, nos séculos anteriores, permitiram-lhe forjar uma cultura econômica útil para os novos tempos.

Vários traços desta cultura já foram citados, outros não e serão objetos de futuras pesquisas. ${ }^{37}$ Seja como for, quando nos debruçamos nestas 
práticas, surgem pistas, no mínimo, instigantes. Isto não só para a sobrevida da nobreza, mas sobre a formação da poderosa comunidade de negociantes de finais do século XVIII carioca. Enfim, aquelas práticas fornecem indícios para a análise de algumas das transformações da sociedade colonial setecentista.

Como vimos, diferentes segmentos das famílias nobres aumentaram suas fortunas com a descoberta das Minas: os Gurgel, os Correia, os Cherem, os Almeida Jordão, os Andrade Soutomaior, os Freire Alemão e outras aparentadas. Portanto, possuíam liquidez para aproveitar o crescimento da economia do Centro-Sul, decorrente do rush do ouro. A tal constatação podemos acrescentar outros vetores. Algumas daquelas famílias mantiveram a hegemonia social sobre a cidade, ocuparam postos-chave na administração, aliaram-se a militares e a comerciantes. A conjugação destes fenômenos leva a crer que eles participaram nas transformações da economia da cidade e, em certo grau, do Centro-Sul, ou, o que é o mesmo, a formação da praça mercantil do Rio, enquanto principal do Império, derivou da elasticidade do que chamo de sociedade de Antigo Regime nos trópicos. Foi, em parte, de seu interior que saíram os mecanismos de acumulação mercantil que mudaram a face da cidade. Por conseguinte, o perfil desta, em finais do século XVIII, não decorreu de uma vitória dos agentes do capital comercial $^{38}$ sobre o que restara da velha sociedade agrária da Guanabara. Na verdade - sem menosprezar os comerciantes vindos do reino e tratando somente das elites - fraçóes da nobreza quinhentista tiveram um papel básico em tal processo. Vejamos estas questôes mais calmamente.

Um dos indícios de tal hipótese é a influência das intrincadas redes de alianças político-parentais sobre a sociedade e a economia. Fenômeno de séculos anteriores, elas permaneceriam como um dos cenários dos personagens do setecentos.

Comecemos pela(s) rede(s) que influía(m) no mercado da cidade, através da Fazenda Real e da Alfândega, ou seja, os Siqueira Cordovil e os Correia Vasques. Curiosamente, os destinos de ambas as famílias se cruzariam, diversas vezes, no tempo. Bartolomeu Cordovil, Provedor da Fazenda Real por várias décadas, ao casar, entrou numa teia parental constituída pelos quinhentistas Homem da Fonseca e os nobres Pimenta de Carvalho, estes com ramificações em Irajá e na Ilha Grande. O filho de Bartolomeu e her- 
deiro do referido ofício, Francisco da Siqueira Cordovil de Melo, foi esposo de Catarina Vaz Moreno, em 1742. Catarina era neta de Manuel Teles Barreto e prima de João Manuel de Melo, ambos aparentados e provenientes do bando Teles/Correia. ${ }^{39}$ Do mesmo bando, sairia Manuel Correia Vasques, o juiz da Alfândega.

Este grupo dominou a paisagem política da segunda metade do seiscentos, passou por dissensões em finais do mesmo, porém continuou como referência no início do século seguinte. Manuel Freire Alemão e José de Andrade Soutomaior eram suas crias - o último tivera rusgas com o bando, na década de 1710 .

Daí a atração exercida pelos integrantes dos Teles/Correia sobre famílias menores da nobreza seiscentista, como os Almeida e os Cherem. Francisco de Almeida Jordão vivera atritos com o visconde de Asseca (Correia), em 1699, pelo controle do trapiche de açúcar. Entretanto, seu filho João Almeida ficara do lado de Manuel Freire Alemão e aliados nas disputas, de 1707, pelo controle da República. Em 1711, uma das primas de João, Catarina Antunes, realizava suas núpcias na capela daquele visconde. No ano de 1748, um sobrinho do mesmo João Almeida, Paulo Pinto de Faria, casou com Bernarda da Silva Montanha, da nobreza paulista e com parentesco nos Pimenta de Carvalho, a mesma dos Cordovil. A filha deste consórcio, também Bernarda, em 1764, virou esposa do juiz da Alfândega Antônio Martins de Brito. Quatro anos antes, a irmã de Antônio Martins de Brito, Escolástica Maria de Oliveira, já estava unida a Francisco Teles Barreto, cuja família detinha o ofício de juiz dos Órfāos. ${ }^{40}$

Voltando no tempo, os elos entre os Almeida Jordão e Martins de Brito datavam de finais da década de 1720, quando foram sócios em negócios ultramarinos. Ao longo dos quarenta anos seguintes, uma teia de núpcias uniria aquelas duas famílias com os Cordovil e os Teles Barreto. Provavelmente, fora em meio àquele contexto que, em 1743, Manuel Vasques renunciava à propriedade do ofício de juiz da Alfândega, em favor de João Martins de Brito, ${ }^{41}$ pai de Antônio e de Escolástica. Completando esta engenharia de alianças de Antigo Regime, temos o casório do desembargador Matias Pinheiro da Silveira Botelho com uma Almeida Jordão, em 1755. 
Quanto a João Cherem, possivelmente comerciante, fora cônjuge, em 1688, de uma filha de criação de Francisco de Sá Soutomaior, provavelmente egresso dos Teles/Correia. Viúvo, João casava com a quinhentista Inez Rangel. Esta, após a morte do esposo, em 1732, uniu-se a Manuel Correia de Brito, primo de Manuel Correia Vasques: ${ }^{42}$ os laços entre os Cherem com os Correia eram renovados.

Assim, tomando por base as décadas entre 1730 e 1750, temos um emaranhado parental, formado por egressos do grande comércio e da nobreza habituada ao poder, e um alto representante da justiça, sendo o eixo deste emaranhado os Teles e os Correia.

Por seu turno, no setecentos, as alianças entre as principais famílias da terra com comerciantes podiam servir de base para tráficos de longa distância na Colônia. Este fora o caso do sargento-mor Manuel da Costa Negreiros, comerciante, cujo raio de ação chegava a Cuiabá. Em 1731, enviara para aquela região nada menos de 49:457\$347 em escravos. Negreiros, desde 1724, era marido de Joana de Campos de Sá, senhora originária de um ramo dos Campos Tourinho, integrantes da antiga governança da terra. Outro ramo dos Campos Tourinho manteve, nos séculos XVII e XVIII, laços com os Sá da Rocha, família de um ex-Ouvidor, vários camaristas e, desde 1720, unida aos Teles Barreto. ${ }^{43}$

No mesmo sentido, temos o caso do capitão Constantino Lobo Cabral de Lacerda, casado, em 1761, com Ana Joaquina, bisneta de uma "exposta" na casa dos Pontes (a mesma dos Teles Barreto). Constantino pertencia — ou a integrou — à tropa dos dragões, sediada em Sacramento, região pecuarista ligada aos mercados coloniais e ao ultramarino. Por ser uma área de fronteira, os oficiais de sua majestade podiam agir mais facilmente como "vis mercadores", pela inexistência de uma Câmara que, bem ou mal, cuidasse dos interesses da República. ${ }^{44}$ Para os militares sulistas, tais matrimônios podiam ter poderosos efeitos na economia política colonial. Afinal, Sacramento estava sob jurisdição do Rio e pelo seu porto saía couro do sul. Isto tudo era facilitado quando os dragões/mercadores podiam contar com autoridades fluminenses.

A ligação com os dragões do sul vinha pelo menos desde princípios do XVIII. Salvo engano, o sogro do provedor Francisco Cordovil, Manuel 
Vaz Moreno, fora capitão em Sacramento, em 1705. Provavelmente, a nobreza fluminense via nestas ligações com militares da fronteira a ampliação geográfica de suas influências políticas e econômicas para muito além do Rio. Seja como for, aquelas alianças parentais viabilizavam, à moda do Antigo Regime, rotas coloniais de longa distância, ou seja, circuitos comerciais baseados numa economia política sustentada por bandos.

Neste sentido, cabe lembrar que, ao lado das rotas comerciais supraregionais, desde o XVII existiam redes políticas que uniam frações de elites de diferentes regiōes. Algumas delas foram há pouco lembradas por meio dos Pimenta de Carvalho. Estas redes, por vincularem as melhores famílias da terra, podiam perfeitamente ligar nobres com ofícios da Coroa. Portanto, deve-se ter mais atenção para a possível conjugação entre tais redes políticas com aquelas rotas comerciais e suas derivaçōes para a acumulação mercantil de longa distância. Por exemplo, são sugestivas as possibilidades de negócios decorrentes de uma aliança/casamento como a da filha Gaspar Rodrigues Paes com Tomé Correia Vasques. Rodrigues Paes possuía grandes lavras em Minas, sendo o guarda-mor da região aurífera, e Tomé era irmão do juiz da Alfândega do Rio. Por seu turno, a dificuldade de realização de empreendimentos, na falta de aliados poderosos em localidades distantes, pode ser ilustrada pelos prejuízos de Costa Negreiros em Cuiabá. Com a morte do seu procurador na cidade, as carregações de fazendas a ele enviadas foram parar nas mãos do tesoureiro de Defuntos, irmão do ouvidor da Vila. Esta delonga se estenderia no mínimo de 1731 a $1733 .{ }^{45}$

No capítulo das uniões da nobreza com oficiais do Rei, merecem destaque especial as núpcias do alferes - e futuro tenente-coronel da guarnição do Rio - João Antunes Lopes Martins, em 1719, com Florência da Guarda Maciel. Uma de suas netas será esposa daquele que se tornará o mais rico negociante "fluminense" de início do século XIX: Braz Carneiro Leão. Desta união sairá parte da elite política do Brasil imperial, entre eles o Marquês do Paraná. ${ }^{46}$

Florência Maciel era de um ramo setecentista, derivado dos Homem da Costa. Entre seus integrantes, temos João e José Maciel da Costa, irmãos da esposa de Lopes Martins. O primeiro era cônjuge, desde de 1723, de Isabel de Menezes; cunhada do neto de João Cherem. O segundo, por volta de 1730, tinha por cara-metade Agueda, rebenta de Antônio Pacheco 
Barreto e Ana Azedias Machado, casal de respeitável patrimônio parental: os Pimenta de Carvalho, os Cordovil, os Freire Alemão e os Teles Barreto, ${ }^{47}$ assim como possuía, via os Cherem, ligações com o capital mercantil. Em resumo, os Maciel estavam ligados a famílias que personificavam epicentros do poder no Rio. Esta engenharia continuaria até finais do século. Uma das cunhadas de Braz Carneiro Leão se casaria com um parente de Constantino Botelho; aquele, unido aos Pontes/Teles Barreto e possuía ligações comerciais com o sul.

Provavelmente, no decorrer da primeira metade do século XVIII, existiram vários circuitos comerciais que uniram o ultramar e o interior do país. Havia o de Francisco Pinheiro e o dos grandes arrematadores reinóis, por exemplo. Ao lado deles, existia o dos Cherem, o dos Almeida Jordão, o dos Costa Negreiros e o de outras. O grau de ligação entre elas é algo ainda a ser investigado. A descoberta do ouro e seus desdobramentos geraram oportunidades de negócios que podiam sustentar diversas associaçóes comerciais. Entretanto, por agirem numa economia de Antigo Regime, estas associações procuravam ter vínculos com oficiais do rei. ${ }^{48}$ Portanto, tais cargos exerciam um papel fundamental nas engrenagens daqueles circuitos. Coisa que, aliás, espero ter deixado claro.

Neste sentido, um fenômeno que aproxima os negociantes acima trabalhados era que tinham em sua base redes político-parentais, vindas da nobreza do Rio, o que lhes garantia o acesso a tais cargos. Com isto, tribunais, como o da alfândega, passavam, em tese, a agir a favor de seus empreendimentos. De igual importância seria analisar os circuitos comerciais e as redes políticas em meio à dinâmica imperial, particularmente considerando que tais redes chegavam a Lisboa. ${ }^{49}$ Este tema adquire maior relevância quando lembramos que as arremataçôes de impostos eram feitas em Lisboa e que os grandes negociantes reinóis recebiam uma especial atenção. ${ }^{50}$

Enfim, na primeira metade do século XVIII existia um Império Ultramarino, já secular: com interesses metropolitanos, circuitos comerciais e grupos políticos estabelecidos. Da mesma forma, havia uma sociedade colonial com sua hierarquia social e suas regras econômicas. Este ambiente foi a base das transformações do período estudado.

Por conseguinte, trata-se de uma época privilegiada para a análise das mudanças e das permanências no Antigo Regime nos trópicos, ou, usando 
uma expressão de W. Kula, para a investigação dos mecanismos de elasticidade da sociedade considerada. Algumas das mudanças já são óbvias para a historiografia e foram vistas neste artigo. Por sua vez, estas modificações ocorreram em um cenário onde prevalecia uma hierarquia de qualidades. Os próprios negociantes enriquecidos continuaram a "investir" em tal sociedade. Compraram engenhos com suas capelas, casaram-se com filhas das melhores famílias da terra e, com isto, procuraram melhorar sua qualidade, ter acesso ao poder. Porém, este é o final da história. Resta saber, de maneira refinada, quais foram os meandros destes processos que, grosso modo, reiteraram a antiga sociedade.

\section{Afogando em nomes: a micro-história tapuia}

Na minha época de estudante, década de 1980, predominava a boa e velha história serial. O que fez minha geração se afogar em números, procurando deslindar a caixa-preta chamada sociedade brasileira. Depois, veio a micro-história italiana, que, sem menosprezar as séries estatísticas, pretendia enxergar a vida escondida pelos números. Com isto, as relações sociais passaram a ser inquiridas sob seus diversos ângulos. As práticas culturais, parentais, econômicas, políticas etc. tornaram-se inseparáveis. Compunham as experiências e as estratégias de pessoas e grupos sociais. Por meio destes fenômenos, podia-se perceber a lógica da sociedade estudada, não mais petrificada, porém em movimento. Para tanto, o método a seguir seria o nome. Escolhidos o objeto de estudo ou os agentes históricos a analisar, caberia segui-los nas múltiplas relações que os formavam, o que significava investigar tais sujeitos em vários tipos de fontes, ou melhor, em todas que retratassem os diversos aspectos - cultural, econômico, político etc. do seu cotidiano. Esta técnica, inevitavelmente, leva a mais nomes, a se afogar em nomes. Entretanto, com tal procedimento, poder-se-ia chegar às relaçōes sociais vivenciadas pelos sujeitos e, ao mesmo tempo, seria aberta uma porta para o entendimento de sua sociedade.

Desnecessário dizer que este método implicou uma releitura das hierarquias sociais. Os grupos sociais deixaram de ser vistos apenas como resultado de relações de produção (em seu sentido mais estrito), para serem portadores de experiências socioculturais, das quais sairiam estratégias de 
vida. Através delas, os diferentes grupos (camponeses, escravos, senhores etc.) entrariam em barganhas e disputas. Enfim, o estudo da reiteração das hierarquias e das relações sociais de produção adquiria mais refinamento.

O que disse acima já foi escrito em verso e prosa por pesquisadores mais habilitados, portanto, não há por que continuar. De mais a mais, aqueles procedimentos e outros podem ser encontrados nos artigos do Quaderni Storici.

Para os primeiros séculos da história colonial brasileira, o uso da microhistória italiana esbarra em obstáculos sérios, entre eles, a fragilidade dos arquivos. Por razões óbvias, a falta de corpus documentais que permitam o rastreamento "das pessoas" em suas múltiplas relações dificulta a análise das experiências sociais. Nestes casos, temos no máximo uma micro-história feia, tapuia, diferente da italiana. Acho que ter claro estes limites impede decepções e ciladas.

Por seu turno, o uso desta micro-história tapuia — como a vejo não implica em abandonar o tempo largo. Os fenômenos sociais/experiências não consistem em processos únicos, repetem-se no tempo, sendo isto produto da "repetição" de certas relações sociais que conformam uma dada sociedade. Caso se pretenda compreender tal recorrência, o recurso é a teoria. Por exemplo, o pesquisador, ao estudar as práticas econômicas ou as estratégias de parentesco, deve procurar a sua reiteração temporal, pois, somente assim, poderá explicá-las. Mesmo a identificação de uma experiência única só é possível através das práticas rotineiras.

De igual modo, o objeto primeiro do historiador é a mudança. Entendo por estrutura, grosso modo, um conjunto interligado de relações sociais reiterativas no tempo, porém com liames sempre tensos. Daí que estrutura é sempre movimento, possui certa elasticidade, que é capaz de absorver novos fenômenos que mudam as suas "feições", sem alterar suas bases. Entretanto, a acumulação destes fenômenos termina por "destruir" a estrutura. Neste sentido, é bom diferenciar mudanças de estruturas, da história de uma estrutura social. Em ambas as situaçôes ocorrem transformações, contudo, em diferentes graus. Os séculos XVII e XVIII foram escravistas, mas diferentes, ou seja, houve mudanças, porém não alterações de estruturas. 
A preocupação com a teoria leva à comparação de "casos". A construção de uma teoria e sua comprovação derivam da comparação de situaçôes. A idéia de que diferentes regiōes coloniais estavam inseridas na sociedade escravista ou de Antigo Regime nos trópicos implica que tais áreas compartilhavam experiências em comum, derivadas da mesma sociedade. Neste sentido, a investigação da formação do Rio de Janeiro colonial pode auxiliar a constituição de Rio Grande de São Pedro, e vice-versa.

O que escrevi resulta das discussões feitas no grupo de história econômica mais acima citado. Isto não implica dizer que todos do grupo compartilhem as mesmas idéias, significa, sim, que há um debate e muito trabalho de campo.

\section{Notas}

${ }^{1}$ Entre outros, cf. Hespanha, A. M. As vésperas do Leviathan. Coimbra: Liv. Almedina, 1994; Elliot, J. H., A Europa of Composite Monarchies. Past and Present, n. 137, 1992; Pujol, G., X. Centralismo e localismo? Sobre as relaçōes políticas e culturais entre capital e territórios nas monarquias européias dos séculos XVI e XVII. Penélope, n. 6, pp. 119142, 1991; Monteiro, N. G. O crepúsculo dos grandes. A casa e o patrimônio da aristocracia em Portugal (1750-1832). Lisboa: Imprensa Nacional / Casa da Moeda, 1998. Para estes autores, por detrás do "Absolutismo", teríamos uma contínua negociação entre o poder central e os locais; estes representados pela aristocracia, pela Igreja, pelas comunas urbanas etc., daí o conceito de Elliot de "monarquias compostas". Além disto, o rei passou a ser entendido como um "grande magistrado", cuja principal função era de manter a "ordem natural", no caso, a estabilidade da ordem pública ou o equilíbrio das forças sociais presentes na sociedade de então.

${ }^{2}$ Greener, Jack. Negociated Authorities. Essays in colonial political and constitutional History. Charlottesville and London: University Press of Virginia, 1994. Para o estudo da sociedade colonial do Brasil, tendo como pano de fundo o Império luso, ver Fragoso, J.; Gouvêa, M. de F. S., Bicalho, M. F. B. Uma leitura do Brasil Colonial — bases da materialidade e governabilidade no império, Penélope, n. 23, pp. 67-88, nov. 2000.

${ }^{3}$ As famílias Velho, Pereira de Almeida, Gonçalves — todas de finais do século XVIII — são exemplos do que chamo de negociantes imperiais, ou seja, cujo raio de ação era o império (Reino, Brasil, África lusa e Goa). Cf. A noção de colonial tardio no Rio de Janeiro e as conexões econômicas do Império português: 1790-1820. In Fragoso, J., Gouvêa, M. de F. S., Bicalho, M. F. B. (Orgs.), O antigo regime nos trópicos: a dinâmica imperial portuguesa (séculos XVI e XVII). Rio de Janeiro: Civilização Brasileira, 2001; Osório, H. Estancieiros, lavradores e comerciantes na constituição da estremadura na América: Rio Grande de São Pedro, 1737-1822. Niterói, PPGHS da UFF, setembro de 1999 (tese de doutorado, iné- 
dita). Evidentemente, outros impérios presenciaram o mesmo fenômeno. Cf. Hancok, D. Citizens of the World - London merchants and the integration of the Britsh Atlantic community, 1735-1785. Cambridge Univertsity Press, 1996; Bowen, H. V. Elites, enterprise and the making of the British Overseas Empire, 1688-1775. London: Macmillam Press, 1996.

${ }^{4}$ Boxer, C. R. O império colonial português. Lisboa: Ed. 70, 1981; Lapa, José Roberto do Amaral. A Bahia na Carreira das Índias. São Paulo: Companhia Editora Nacional, 1968; Thomaz, L. De Ceuta a Timor. Lisboa: Difel, 1994; Subrahmanyam, S. O Império Asiático Português, 1500-1700. Uma História Política e Econômica. Lisboa: Difel, 1995; Fragoso, João. Homens de grossa aventura: 1790-1830. 2. ed.Rio de Janeiro: Civilização Brasileira, 1998; Florentino, Manolo. Em Costas Negras. 2. ed. São Paulo: Companhia das Letras, 1997; Fragoso, J.; Gouvêa, M. de F. S., Bicalho, M. F. B. Op. cit., 2001. Sobre o papel das câmaras, ver Bicalho, M. F. A cidade e o Império: Rio de Janeiro na dinâmica colonial portuguesa. Séculos XVII e XVIII. São Paulo, FFLCH da USP (tese de doutoramento, inédita), 1997.

${ }^{5}$ Cf. Subrahmanyam, S. Op. cit. para o Estado da Índia. No caso da América portuguesa, ver Boxer, C. R.Salvador de Sá e a luta pelo Brasil e Angola, 1602-1686. Rio de Janeiro: Brasiliana, 1973.

${ }^{6}$ Para a ampliação geográfica destes circuitos comerciais no Centro-Oeste e no Sul, ver, respectivamente, Godoy, S. A. Itu e Araritaguara na rota das Monçóes (1718 a 1838). Campinas, Programa de Pós-Graduação em História Econômica (dissertação de mestrado, inédita), 2002; Hamaister, M. D. O continente do Rio Grande de São Pedro: os homens, suas redes de relaçôes e suas mercadorias semoventes, c.1727 - c.1763. Rio de Janeiro, PPGHIS-UFRJ (dissertação de mestrado, inédita) 2002.

${ }^{7}$ No caso do Rio de Janeiro, ver Sampaio, Antônio C. J. Na curva do tempo, na encruzilhada do Império. Hierarquização social e estratégias de classe: a produção da exclusão (Rio de Janeiro, c.1650 - c.1750). Niterói, PPGHS da UFF (tese de doutorado, inédita), 2000; Barreto, D. A qualidade do artesão: contribuição ao estudo da estrutura social e mercado interno na cidade do Rio de Janeiro, c.1690- c.1750. Rio de Janeiro, PPGHIS-UFRJ (dissertação de mestrado, inédita), 2002.

${ }^{8} \mathrm{O}$ estudo da hierarquia colonial terá como ponto de partido deliberado a sua elite.

${ }^{9}$ Ver, sobre o tema: Fragoso, J. Um mercado dominado por "bandos": ensaio sobre a lógica econômica da nobreza da terra do Rio de Janeiro Seiscentista. In Silva, F. C. T. da; Mattos, H. M., Fragoso, J. (Orgs.). Escritos sobre História e Educação: homenagem à Maria Yedda Linhares, Rio de Janeiro: Mauad; FAPERJ, 2001.

${ }^{10}$ Para Portugal ver Monteiro, N. G. O crepúsculo dos grandes. A casa e o patrimônio da aristocracia em Portugal (1750-1832), Lisboa: Imprensa Nacional / Casa da Moeda, 1998. Para o Rio de Janeiro Cf. Fragoso, J. Op. cit.

${ }^{11} \mathrm{Na}$ segunda metade do século XVII, os grandes empresários cristãos-novos provavelmente eram os mais ricos da cidade, porém muitos deles não pertenciam à governança da terra, como é o caso de José Gomes da Silva. Isto não pela ascendência judia, pois muitas 
das melhores famílias possuíam essa origem, mas por não pertencerem à velha estirpe de conquistadores; ver Fragoso, J. A formação da economia colonial no Rio de Janeiro e de sua elite senhorial (séculos XVI e XVII). In Fragoso, J., Gouvêa, M. de F. S. \& Bicalho, M. F. B. (Org.). O antigo regime nos trópicos: a dinâmica imperial portuguesa (séculos XVI e XVII). Rio de Janeiro: Civilização Brasileira, 2001.

${ }^{12}$ Cf. Ellis, A. Jr. Os primeiros troncos paulistas. São Paulo, Nacional, 1976. pp. 191-192 (Brasiliana, 59). Fragoso, J. A nobreza da República: notas sobre a formação da primeira elite senhorial do Rio de Janeiro. Topoi, n. 1, pp. 45-122, 2000.

${ }^{13}$ Nóbrega, M. da. Cartas Jesuiticas 1 - Cartas do Brasil. Belo Horizonte; Sãod Paulo: Itatiaia/Edusp, 1988. Luís, Washington. Na Capitania de São Vicente. São Paulo: Livraria Martins Editora, 1956. p. 151; Fragoso, J. A formação da economia colonial no Rio de Janeiro e de sua elite senhorial (séculos XVI e XVII). In Fragoso, J., Gouvêa, M. de F. S. \& Bicalho, M. F. B. (Org.). O antigo regime nos trópicos: a dinâmica imperial portuguesa (séculos XVI e XVII). Rio de Janeiro: Civilização Brasileira, 2001; Hamaister, M. D. Op. cit. ${ }^{14}$ A pesquisa de Hamaister, sobre o Rio Grande São Pedro setecentista, demonstrou a presença de uma vasta rede de alianças parentais entre segmentos da elite gaúcha com as de São Paulo (cf. Hamaister. Op. cit.). Gil, numa investigação em curso sobre a mesma região e século, constata no contrabando a cumplicidade entre nobres da terra, comerciantes e autoridades reinóis (cf. Gil, T. O mercado muar platino e a criação de mulas no Rio Grande de São Pedro colonial: 1730-1800. Rio de Janeiro, PPGHIS-UFRJ, 2002 (pesquisa de mestrado). Para o Rio de Janeiro seiscentista, cf. Fragoso, J. Fidalgos, flecheiros e o mundo atlântico: Rio de Janeiro no século XVII. Rio de Janeiro: Departamento de História - UFRJ, 2002. (relatório de pesquisa). Saindo do ambiente colonial, Martins e Marinho pesquisam as estratégias das elites no século XIX, respectivamente, regional e imperial (cf. Martins, M. F.V. O Conselho de Estado no Brasil imperial. Rio de Janeiro, PPGHIS-UFRJ, 2002; Marinho, L. Elites econômicas em Belém, 1850-1870. Rio de Janeiro, PPGHIS-UFRJ, 2002 (pesquisa de mestrado). O conjunto destes estudos fornecerá um amplo panorama sobre a exclusão social.

${ }^{15}$ Fragoso, J. "Um mercado dominado por "bandos": ensaio sobre a lógica econômica da nobreza da terra do Rio de Janeiro Seiscentista. In Silva, F. C. T. da; Mattos, H. M., Fragoso, J. (Orgs.). Escritos sobre História e Educação: homenagem à Maria Yedda Linhares, Rio de Janeiro: Mauad; FAPERJ, 2001.

${ }^{16}$ Cf. Machado, Cacilda da Silva. Casamentos interétnicos no Paraná, século XVIII. Rio de Janeiro. PPGHIS-UFRJ, 2002 (pesquisa de doutorado). Machado investiga situações de matrimônios mistos no Paraná setecentista, em alguns dos quais as "trocas" entre grupos de diferentes qualidades fica patente.

${ }^{17}$ Cf. Levi, Giovanni. Comportamentos, recursos, processos antes da "revolução" do consumo. In Revel, Jacques. Jogos de escalas. Rio de Janeiro: FGV, 1998. Para um estudo das estratégias familiares de lavradores escravistas, ver Muniz, Célia A pequena produção agrícola e práticas familiares no Vale do Paraíba Fluminense, Rio de Janeiro, 1850-1900. Rio de Janeiro, 2002, PPGHIS-UFRJ (pesquisa de doutorado). 
${ }^{18}$ Para a escravidão brasileira já há uma vasta literatura sobre a existência de práticas culturais produzidas pelos cativos. Ver, em particular, o grupo de História Social da Cultura da Unicamp.

${ }^{19}$ Cf. Ferreira, R. G. Trabalho Artesanal e mobilidade social no Rio de Janeiro da primeira metade do século XIX. Rio de Janeiro, 2002, PPGHIS-UFRJ (pesquisa de doutorado). Ferreira pesquisa estes temas e localizou famílias de forros que se transformaram em donos de moendas, porém nem sempre perdiam a cor, isto é, continuavam a ser encarados como pardos. Esta investigação ainda está em curso, portanto, sujeita a mudanças. Uma de suas preocupações é analisar como os "pardos" enriquecidos encaravam tal processo e como a sociedade os via.

${ }^{20}$ Fragoso, J. Op. cit.

${ }^{21}$ AHU, CA, cx. 9, doc. 1.779.

${ }^{22}$ AHU, CA, cx. 55, doc. 12.945.

${ }^{23}$ Impostos em 1700, ver AHU, CA, cx. 12, doc. 2.399. Sobre a natureza de segunda classe da economia fluminense cf. Fragoso, Fidalgos, flecheiros e o mundo atlântico: Rio de Janeiro no século XVII. Rio de Janeiro: Departamento de História — UFRJ, 2002. (relatório de pesquisa).

${ }^{24}$ AHU, Rio de Janeiro, códice 1269.

${ }^{25}$ Para o envolvimento do Rio na procura de metais, ver Boxer, Salvador. Op. cit., passim. Quanto à participação da nobreza da terra fluminense como sertanistas ver o exemplo da expedição do mestre-de-campo João Correia de Sá, de meados do século XVII, que contou com os Azeredo Coutinho (cf. AN. PF, cód. 60, vol. 3). Sobre as ligaçōes parentais entre as nobrezas do Rio e de São Paulo, ver os Tasques Pompeu com os Gurgel do Rio, e dos Bueno, e outras famílias paulistas com os Rendon fluminenses: cf. Paes Leme, Pedro, T. A. Nobiliarquia paulistana histórica e genealógica. Belo Horizonte; São Paulo: Itatiaia; Edusp, t. 1, pp. 111-122, t. 2, pp. 249-293. Este movimento de procura do ouro fora, ainda, mais acentuado com o declínio do preço internacional do açúcar. Cf. Schawartz, Stuart, Pécora, Alcir. As excelências do governador. São Paulo: Companhia das Letras, 2002.

${ }^{26}$ Carta de Gaspar Rodrigues Paes. AHU, CA, doc. 3.093.

27 Sobre a noção de cultura econômica, ver Grendi, Edoardo. Associazioni familiari e associazioni d'affari. Quaderni Storici, Genova, Il Mulino, pp. 23-39, anno XXXI, n. 91, fasc. 1. 1996; José de Andrade Soutomaior - AHU, CA, cx. 25, doc. 5.657-58; Manuel Freire Alemão e Francisco Oliveira Paes - CA, cx. 24, doc. 5.536; Francisco do Amaral Gurgel, CA, cx. 16, doc. 3.317; Sampaio, A.Op. cit.; Francisco de Almeida Jordão - CA, cx.12, doc. 2.211, 1699. Rheingantz, Carlos. Primeiras famílias do Rio de Janeiro. Rio de Janeiro: Livraria Brasiliana, 1965. Vol. 1, p. 374.

${ }^{28}$ Luís Vahia Teixeira Miranda - AHU, CA, cx. 50, doc. 11.782; Manuel Botelho de Lacerda - AHU, CA., cx. 752, doc. 12.183.

${ }^{29}$ Governador Francisco da Távora - AHU, CA, cx. 16, doc. 3.355-57.

${ }^{30}$ AHU, CA, cx. 21, doc. 4.733, 1725.

${ }^{31}$ Rheingantz, C. Op. cit., vol. 1, pp. 39 e 335. 
${ }^{32}$ CF. Bicalho, M. F. Op. cit.; AHU — Rio de Janeiro, cód. 1.294.

${ }^{33}$ Manuel Correia Vasques - AHU, CA, cx. 13, doc. 2.716; Bartolomeu da Serqueira Cordovil - AHU, CA, cx. 17, doc. 3.519. Rheingantz, C. Op. cit., Vol. 2, p. 151.

${ }^{34}$ Apud Furtado, Júnia. Homens de negócios. São Paulo: FFLCH — USP, 1996 (tese de douorado). p. 109.

${ }^{35}$ Bartolomeu da Siqueira Cordovil - AHU, CA, cx. 22, doc. 5.024; Manuel Correia Vasques - CA, cx. 23, doc. 5.202; cx. 23, doc. 5.270; Francisco Cordovil Siqueira de Mello, CA, cx. 43, doc. 10.049; Antônio Martins de Brito, CA, cx. 81, doc. 18.818. Cf. Rheingantz, C. Op. cit., Vol. 1, p. 41; Matias Pinheiro da Silveira Botelho, CA, cx. 70, doc. 16.201 .

36 Por exemplo, quando Dauvegner, em 1735, se desentendeu com Francisco Cordovil, os procuradores do primeiro, no Rio, o defenderam, entre eles Ignácio Jordão de Almeida e João Martins de Brito. Cordovil e Almeida pertenciam à nobreza e, posteriormente, os filhos de Brito nela entrariam. Sobre as divergências entre a nobreza ou, pelo menos, parte dela, com os negociantes, em meados do setecentos, ver Bicalho, M. F. Op. cit.

${ }^{37}$ Estas práticas, como os cuidados com a manutenção do poder local, continuariam ao longo do século. Um bom exemplo disto é a compra de engenhos entre nobres do mesmo bando. Em 1733, João Freire Alemão comprava o engenho da viúva de João Manuel de Melo, sua aparentada. AHU, CA. cx. 34, doc. 7.996. Uma estratégia que merece maior atenção é o envio de parentes para regiões de "fronteira", como Minas e o sul. Estes movimentos aumentavam o cabedal da família e lhe davam mais proeminência política no Rio. Tal foi o caso dos Fagundes e dos Andrade Soutomaior. Cf. Rheingantz, C. Op. cit. Vol. 1, p. 92; vol. 2, pp. 7-8.

${ }^{38}$ Um tema que merece uma atenção especial é a atuação dos consignatórios dos grandes mercadores do Rio. Nas cartas de Francisco Pinheiro, foram comuns queixas contra seus representantes na América, acusados de fazerem negócios próprios em detrimento do "patrão". Cite-se João Francisco Muzzi, principal agente de Pinheiro, e João Lopes. As descendentes do último se casariam com a futura fina flor dos negociantes do Rio de finais do século XVIII, como Antônio Ribeiro Avelar, Francisco Xavier Pires e Antônio dos Santos. Cf. Lisanti, L. Negócios Coloniais: uma correspondência comercial do século XVIII. Brasília: Ministério da Fazenda, 1973. Vol. 5, pp. 339-41, 345 e passim; Rheingantz, C. Op. cit.

${ }^{39}$ Cf. Rheingantz, C. Op. cit., Vol. 2, pp. 7, 513 e 520. Sobre o bando Teles/Correia, ver Fragoso, J. Um mercado dominado por "bandos": ensaio sobre a lógica econômica da nobreza da terra do Rio de Janeiro Seiscentista. In Silva, F. C. T. da; Mattos, H. M., Fragoso, J. (Orgs.). Escritos sobre História e Educação: homenagem à Maria Yedda Linhares, Rio de Janeiro: Mauad; FAPERJ, 2001.

${ }^{40}$ João Mendes de Almeida - AHU, CA, cx. 12, doc. 3.154; Rheingantz, C. Op. cit. Vol. 1, pp. 69-70, p. 40 e vol. 3, p. 176.

${ }^{41}$ AHU, CA, cx. 51, doc. 11.996.

${ }^{42}$ Rheingantz, C. Op. cit., Vol. 1, p. 335 e 371-372. 
${ }^{43}$ Rheingantz, C. Op. cit., Vol. 1, p. 289 e Vol. 2, p. 499. No século XVIII, por meio dos Sá da Rocha, Eugênia Campos Tourinho tornou-se concunhada de Clara Barboza e Menezes (Teles). DI, p. 170. Agradeço a Silvana Gody a indicação do referido comerciante. ${ }^{44} \mathrm{O}$ pai de Constantino, Manuel Botelho de Lacerda, fora mestre-de-campo em Sacramento, exercera o posto de juiz da Alfândega da região e estivera à frente de vários negócios na regiāo. Cf. Prado, F. P. Colônia do Sacramento: Comércio e Sociedade na Fronteira Platina (1716 - 1753). Porto Alegre: Programa de Pós-Graduação em História da UFRGS, 2002. (Dissertação de Mestrado inédita).

${ }^{45}$ DI, pp. 167-170.

${ }^{46}$ Rheingantz, C. Op. cit., vol. 1, pp. 341-343. João Antunes Lopes Martins - AHU, CA, cx. 76, doc. 17640; CA, cx. 79, doc. 19.241.

${ }^{47}$ Rheingantz, C. Op. cit., vol. 1, pp. 73 e 142, vol. 2, pp. 6-7, 495-496.

${ }^{48}$ Cf. Furtado, Júnia. Op. cit. passim. Na correspondência de Francisco Pinheiro, a aquisição de postos como o de escrivão da ouvidoria e de patrão-mor do porto era um assunto comum. Cf. Lisanti, L. Op. cit. passim.

${ }^{49}$ Estas ligaçōes entre bandos da cidade com facções em Lisboa foram corriqueiras no século XVII (cf. Fragoso, J. A formação da economia colonial no Rio de Janeiro e de sua elite senhorial (séculos XVI e XVII). In Fragoso, J., Gouvêa, M. de F. S. \& Bicalho, M. F. B. (Org.). O antigo regime nos trópicos: a dinâmica imperial portuguesa (séculos XVI e XVII). Rio de Janeiro: Civilização Brasileira, 2001. Em 1709, o ouvidor do Rio, João da Costa da Fonseca, acusava o governador Fernando Martins M. Lencastre de várias irregularidades, nas quais se valeria de alianças com o conde de Óbitos. Em tal disputa estava em jogo o controle da política e da economia da cidade. O ouvidor pertencia ao bando Teles/Barreto e o governador, aos grupos adversários. AHU, CA., cx. 15, doc. 3.150-3.161.

${ }^{50}$ Cf. Pedreira, J. Os homens de negócio da Praça de Lisboa de Pombal ao Vintismo (17551822). Lisboa, Universidade Nova de Lisboa, 1995 (tese de doutorado, inédita).

\section{Fontes Primárias}

AHU - Arquivo Histórico Ultramarino. Coleção Rio de Janeiro. CA — Castro Almeida, av. — documentos avulsos. Códice 1.279 - Relação de todos os contratos e mais rendas na Capitania do Rio de Janeiro por suas origens e criações, 1733.

AN — Arquivo Nacional. cód. — códices, Provedoria da Fazenda Real do Rio de Janeiro.

DI - Arquivo do Estado de São Paulo. Documentos Interessantes para a História e Costumes de São Paulo, vol. XIII, São Paulo, 1902.

SALVADOR, Frei Vicente. História do Brasil. Belo Horizonte; São Paulo, Itatiaia; Edusp,1982. 
NÓBREGA, Manuel da. Cartas Jesuiticas 1 - Cartas do Brasil. Belo Horizonte; São Paulo, Itatiaia; Edusp, 1988.

\section{Resumo}

O texto expõe preocupaçôes temáticas do grupo de história econômica (séculos XVIIXIX), sob minha orientação, no LIPHIS e no PPGHIS. É dada especial atenção para os seguintes temas: império português, hierarquia social e processos de mudanças na sociedade colonial. O texto termina por apresentar questōes metodológicas de pesquisa debatidas no grupo. Várias das idéias a seguir são hipóteses de investigaçôes ainda em curso e, portanto, sujeitas a reparos.

\section{Abstract}

This text presents some of the subjects approched by the economic history group (XVIIth$X X$ th centuries), under my coordination at the Laboratório Interdisciplinar de Pesquisa em História Social (LIPHIS) and the Programa de Pós-graduação em História Social (PPGHIS). We took a special attention to the following questions: the portuguese Empire, social hierarchy and chaning process in the colonial society. The article introduces some methodological problems and technics of research discussed by he group. Many of the ideas exposed are hypothesis of the researches in course. 